\title{
Global distribution of a key trophic guild contrasts with common latitudinal diversity patterns
}

\author{
Luz Boyero, ${ }^{1,2,23}$ Richard G. Pearson, ${ }^{2}$ David Dudgeon, ${ }^{3}$ Manuel A. S. Graça, ${ }^{4}$ Mark O. Gessner, ${ }^{5,6,24}$ \\ Ricardo J. Albariño, ${ }^{7}$ Verónica Ferreira, ${ }^{4}$ Catherine M. Yule, ${ }^{8}$ Andrew J. Boulton, ${ }^{9}$ \\ Muthukumarasamy Arunachalam, ${ }^{10}$ Marcos Callisto, ${ }^{11}$ Eric Chauvet, ${ }^{12,13}$ Alonso Ramírez, ${ }^{14}$ \\ Julián Chará, ${ }^{15,16}$ Marcelo S. Moretti, ${ }^{11,25}$ José F. Gonçalves, Jr., ${ }^{11,26}$ Julie E. Helson, ${ }^{17}$ \\ Ana M. Chará-Serna, ${ }^{15,18}$ Andrea C. Encalada, ${ }^{4,19}$ Judy N. Davies, ${ }^{9}$ Sylvain Lamothe, ${ }^{12,13}$ Aydeè Cornejo, ${ }^{20,21}$ \\ Aggie O. Y. Li, ${ }^{3}$ Leonardo M. Buria, ${ }^{7}$ Verónica D. Villanueva, ${ }^{7}$ María C. Zúñiga, ${ }^{15}$ \\ and Catherine M. Pringle 22 \\ ${ }^{1}$ Wetland Ecology Department, Doñana Biological Station-CSIC, Avda Americo Vespucio sn $/ n$, E-41092 Sevilla, Spain \\ ${ }^{2}$ School of Marine and Tropical Biology, James Cook University, Townsville, Queensland 4811 Australia \\ ${ }^{3}$ School of Biological Sciences, The University of Hong Kong, Hong Kong SAR, China \\ ${ }^{4}$ IMAR-CMA and Department Life Sciences, University of Coimbra, 3001401 Coimbra, Portugal \\ ${ }^{5}$ Department of Aquatic Ecology, Eawag: Swiss Federal Institute of Aquatic Science and Technology, \\ Überlandstrasse 133, 8600 Dübendorf, Switzerland \\ ${ }^{6}$ Institute of Integrative Biology (IBZ), ETH Zurich, 8092 Zurich, Switzerland \\ ${ }^{7}$ Laboratorio de Limnología, INIBIOMA, Universidad Nacional del Comahue-CONICET, Bariloche, Argentina \\ ${ }^{8}$ School of Science, Monash University, Jalan Lagoon Selatan, Bandar Sunway, 46150, Selangor, Malaysia \\ ${ }^{9}$ Ecosystem Management, School of Environmental and Rural Science, University of New England, Armidale, NSW 2350, Australia \\ ${ }^{10}$ Sri Paramakalyani Centre for Environmental Sciences, Manonmainam Sundaranar University, Alwarkuruchi, Tamil Nadu, India \\ ${ }^{11}$ Laboratório de Ecologia de Bentos, Instituto de Ciências Biológicas, Universidade Federal de Minas Gerais, \\ CP 486, CEP 30.161-970, Belo Horizonte MG, Brazil \\ ${ }^{12}$ Université de Toulouse, INP, UPS, EcoLab (Laboratoire Écologie Fonctionnelle et Environnement), \\ 118 Route de Narbonne, 31062 Toulouse, France \\ ${ }^{13}$ CNRS, EcoLab (Laboratoire Ecologie Fonctionnelle et Environnement), 118 Route de Narbonne, 31062 Toulouse, France \\ ${ }^{14}$ Institute for Tropical Ecosystem Studies, University of Puerto Rico, P.O. Box 70377, San Juan, Puerto Rico 00936 USA \\ ${ }^{15}$ Centro para la Investigación en Sistemas Sostenibles de Producción Agropecuaria, CIPAV, Carrera 25 No. 6-62, Cali, Colombia \\ ${ }^{16}$ Centro de Investigaciones y Estudios en Biodiversidad y Recursos Genéticos, CIEBREG, POB 97, Pereira, Colombia \\ ${ }^{17}$ Surface and Groundwater Ecology Research Group, Department of Biological Sciences, University of Toronto at Scarborough, \\ 1265 Military Trail, Toronto, Ontario M1C 1A4 Canada \\ ${ }^{18}$ Departamento de Biología, Grupo de Investigaciones Entomológicas, Universidad del Valle, Apartado Aéreo 25360, Cali, Colombia \\ ${ }^{19}$ Colegio de Ciencias Biológicas y Ambientales, Universidad San Francisco de Quito, Campus Cumbayá, \\ P.O. Box 171200841 , Quito, Ecuador \\ ${ }^{20}$ Sección de Entomología, Instituto Conmemorativo Gorgas de Estudios de la Salud, Avenida Justo Arosemena y Calle 35, 081602593, \\ Panama City, Panama \\ ${ }^{21}$ Programa Centroamericano de Maestría en Entomología, Universidad de Panamá, Panama City, Panama \\ ${ }^{22}$ Odum School of Ecology, The University of Georgia, Athens, Georgia 30602-2602 USA
}

Abstract. Most hypotheses explaining the general gradient of higher diversity toward the equator are implicit or explicit about greater species packing in the tropics. However, global patterns of diversity within guilds, including trophic guilds (i.e., groups of organisms that use similar food resources), are poorly known. We explored global diversity patterns of a key trophic guild in stream ecosystems, the detritivore shredders. This was motivated by the fundamental ecological role of shredders as decomposers of leaf litter and by some records pointing to low shredder diversity and abundance in the tropics, which contrasts with diversity patterns of most major taxa for which broad-scale latitudinal patterns haven been examined. Given this evidence, we hypothesized that shredders are more abundant and diverse in temperate than in tropical streams, and that this pattern is related to the higher temperatures and lower availability of high-quality leaf litter in the tropics. Our comprehensive global survey (129 stream sites from 14 regions on six continents) corroborated the expected

Manuscript received 19 November 2010; revised 8 March 2011; accepted 23 March 2011. Corresponding Editor: W. V. Sobczak. 23 E-mail: luz.boyero@ebd.csic.es

${ }^{24}$ Present address: Department of Stratified Lakes, Leibniz Institute of Freshwater Ecology and Inland Fisheries (IGB), Alte Fischerhütte 2, 16775 Stechlin, Germany, and Department of Ecology, Berlin Institute of Technology (TU Berlin), ErnstReuter-Platz 1, 10587 Berlin, Germany.

25 Present address: Centro Universitário Vila Velha, Programa de Pós Graduação em Ecologia de Ecossistemas, 29102770, Vila Velha, ES, Brazil.

${ }_{26}$ Present address: Laboratório de Limnologia, Departamento de Ecologia, IB, Universidade de Brasília, 70910900 , Brasília, DF, Brazil. 
latitudinal pattern and showed that shredder distribution (abundance, diversity and assemblage composition) was explained by a combination of factors, including water temperature (some taxa were restricted to cool waters) and biogeography (some taxa were more diverse in particular biogeographic realms). In contrast to our hypothesis, shredder diversity was unrelated to leaf toughness, but it was inversely related to litter diversity. Our findings markedly contrast with global trends of diversity for most taxa, and with the general rule of higher consumer diversity at higher levels of resource diversity. Moreover, they highlight the emerging role of temperature in understanding global patterns of diversity, which is of great relevance in the face of projected global warming.

Key words: global distribution pattern; latitudinal diversity gradient; leaf litter quality; shredder detritivores; stream ecosystems.

\section{INTRODUCTION}

Increasing diversity toward the tropics is a pattern shared across a broad range of major taxa (Hillebrand 2004). There are many postulated explanations for this gradient (Willig et al. 2003), most of which are implicit or explicit about greater species packing in the tropics (Arita and Vázquez-Domínguez 2008). In other words, it is generally assumed that, in tropical areas, there is enhanced taxonomic richness within groups of organisms that use similar resources (i.e., guilds), including food resources (i.e., trophic guilds). However, broadscale studies of diversity across latitudinal gradients have focused on taxonomic groups (e.g., Stevens 2004, Quian and Ricklefs 2007, Fuhrman et al. 2008, Pearson and Boyero 2009, Passy 2010), while there are no comparable studies on trophic guilds. Exploring diversity patterns within trophic guilds can reduce confounding variation across all available food resources, and it focuses more directly on mechanisms driving diversity.

Forest streams are suitable systems to study diversity patterns within trophic guilds (often designated as functional feeding groups, sensu Cummins and Klug 1979) because food webs in these ecosystems typically rely on detritus-based pathways and are numerically dominated by a restricted number of detritivore trophic guilds (Cummins et al. 1989). Among these guilds, the shredders play a key ecological role as they are major contributors to leaf litter decomposition (Graça 2001, Hieber and Gessner 2002). Their feeding activities produce large amounts of fine particulate organic matter (Cummins 1974) that is used by other detritivore guilds (Heard and Richardson 1995), and they incorporate allochthonous carbon and nutrients into animal biomass (Chung and Suberkropp 2009), thus making it available for higher trophic levels (Wallace et al. 1997).

Shredder diversity patterns across latitudes are of particular interest because evidence from multiple local studies suggests a pattern opposite to the general increase in diversity toward the tropics, as well as notably lower shredder abundances in tropical streams (e.g., Dudgeon 1994, Dobson et al. 2002, Mathuriau and Chauvet 2002, Gonçalves et al. 2006, Li and Dudgeon 2008). This has led to the notion that biologically driven decomposition in tropical streams is almost entirely due to microorganisms, unlike in temperate streams, in which shredders are often key decomposition agents (Hieber and Gessner 2002). One of the main hypotheses proposed to explain this pattern is that shredders are evolutionarily adapted to cool waters, and therefore scarce in the tropics for physiological reasons (Dobson et al. 2002). Another hypothesis suggests that palatable leaves are scarce in tropical streams because of a combination of high riparian tree diversity and leaves that are better defended against herbivory (Coley and Barone 1996, Cornwell et al. 2008, Coq et al. 2010) defenses that remain after abscission (Grime et al. 1996) and thus are encountered by stream shredders (see Plate 1) (Wantzen et al. 2002).

To date, hypotheses explaining differences in shredder occurrence between temperate and tropical streams remain largely untested, and studies of shredder distribution using comparable methods over a broad range of latitudes are lacking. The need for such global studies is reinforced by several recent tropical studies that have found high numbers of shredders (Cheshire et al. 2005, Landeiro et al. 2008, Camacho et al. 2009, Yule et al. 2009), and thus question the generally accepted pattern of shredders being scarce in the tropics (Boyero et al. 2009). Against this background, we examined the shredder fauna of multiple stream sites around the world and examined their relationship with water temperature and the diversity and toughness of naturally entrained leaf litter. Our a priori hypotheses were (1) that shredders are more abundant and diverse in temperate than in tropical streams and (2) that shredder distribution in tropical streams is limited by high temperatures and low proportions of palatable litter resulting from a great diversity of riparian trees with tough leaves.

\section{Methods}

\section{Sampling}

We surveyed 129 sites from 14 regions in six continents across five biogeographic realms (following the terminology of Vinson and Hawkins 2003, after Udvardy 1975), at latitudes ranging from $43^{\circ} \mathrm{N}$ to $41^{\circ} \mathrm{S}$ (Table 1). All surveys were carried out in 2006 and 2007. In each region we sampled 5-12 sites (mostly 10), each located in a different headwater stream with little or no human impact. Stream width was $\leq 10 \mathrm{~m}$ and site length was approximately 10 times the stream width (50-100 
TABLE 1. Study regions, region acronyms, range of latitude (degrees from the equator) in each region, zone ( $\mathrm{T}$, temperate; Tr, tropical), and biogeographic (biog.) realm (Af, Afrotropical; Au, Australian; I, Indomalayan; N, Neotropical; P, Paleartic).

\begin{tabular}{|c|c|c|c|c|}
\hline Study region & Acronym & Latitude & Zone & Biog. realm \\
\hline Malaysia (various regions) & MLY & $00.03-04.42$ & $\operatorname{Tr}$ & I \\
\hline Ecuador (montane Andean forest) & ECD & $00.09-00.13$ & $\operatorname{Tr}$ & $\mathrm{N}$ \\
\hline Colombia (western Andean region) & $\mathrm{COL}$ & $04.71-04.89$ & $\operatorname{Tr}$ & $\mathrm{N}$ \\
\hline India (southern Western Ghats) & IND & $08.01-11.60$ & $\operatorname{Tr}$ & I \\
\hline Panama (Campana N.P. and Soberanía N.P.) & PAN & $08.68-09.17$ & $\mathrm{Tr}$ & $\mathrm{N}$ \\
\hline Costa Rica (La Selva Biological Station) & CRA & $10.41-10.43$ & $\mathrm{Tr}$ & $\mathrm{N}$ \\
\hline Queensland, Australia (Australian wet tropics) & QLD & $17.15-19.00$ & $\operatorname{Tr}$ & $\mathrm{Au}$ \\
\hline Brazil (Minas Gerais) & BRL & $18.05-20.50$ & $\operatorname{Tr}$ & $\mathrm{N}$ \\
\hline Puerto Rico (El Verde Field Station) & $\mathrm{PRC}$ & $18.32-18.32$ & $\operatorname{Tr}$ & $\mathrm{N}$ \\
\hline China (Hong Kong) & HKN & $22.38-22.50$ & $\mathrm{Tr}$ & I \\
\hline New South Wales, Australia (Coffs Harbour Hinterland) & NSW & $30.23-30.45$ & $\mathrm{~T}$ & $\mathrm{Au}$ \\
\hline Portugal (Lousã and Caramulo Mountains) & PTG & $40.07-40.60$ & $\mathrm{~T}$ & $\mathrm{P}$ \\
\hline Argentina (northern Patagonia Andes) & ARG & $40.46-41.25$ & $\mathrm{~T}$ & $\mathrm{~N}$ \\
\hline France (Montagne Noire) & FRN & $43.39-43.49$ & $\mathrm{~T}$ & $P$ \\
\hline
\end{tabular}

Note: "N.P." indicates National Park.

$\mathrm{m})$. At each site, we generally took 10 leaf litter samples, half from pools and half from riffles, from within areas of $20 \times 20 \mathrm{~cm}$ in a litter layer no deeper than $4 \mathrm{~cm}$. We used a $0.5-\mathrm{mm}$ mesh net, and transferred the litter to labeled press-zipper plastic bags. Samples were kept cool and transported to the laboratory, where they were rinsed and carefully inspected for invertebrates.

\section{Invertebrates}

Invertebrates retained on a $250-\mu \mathrm{m}$ screen were sorted and preserved in $70 \%$ ethanol. They were counted, separated into morphospecies, and identified to the lowest taxonomic level possible (see Appendix A). A similar degree of efficiency in the separation of morphospecies was ensured by consulting local experts. Morphospecies were assigned to shredder or nonshredder categories through gut content analysis as described in Cheshire et al. (2005). Although classification of stream invertebrates into functional feeding groups refers to feeding mode rather than food type (Cummins and Klug 1979), and thus generally requires examination of mouth parts, detritivore shredders can be identified solely by their gut contents because they are the only stream invertebrates with vascular plant tissue (leaf or wood fragments) $>1 \mathrm{~mm}$ in their guts.

\section{Climatic variables and leaf litter}

Water temperature was recorded in situ at each study site at the time of sample collection. Additionally, the monthly mean, minimum, and maximum air temperature for the preceding 5-30 years was obtained from the nearest weather station in each region and used to calculate the mean temperature of the coldest and hottest month, and the coefficient of variation of mean monthly temperature as a measure of seasonal variability. The number of plant species in leaf litter samples was estimated by visually distinguishing morphospecies (using local expertise). Leaf litter was then oven dried to constant mass $\left(60-80^{\circ} \mathrm{C}\right.$ for at least $\left.48 \mathrm{~h}\right)$ and weighed. The number of riparian tree morphospecies at each site was visually estimated, using characters such as bark texture, leaf size and shape, and tree form, and the three most common were selected to measure leaf toughness (except in Brazil and Colombia; see Appendix B for a list of tree species and leaf toughness values). In regions with a large number of common species (most tropical sites), three were randomly chosen among the species with the most abundant leaf litter in the stream. Leaf toughness was measured with a standardized penetrometer (identical devices mailed to all project partners), which allows determination of the pressure (in $\mathrm{kPa}$ ) necessary to pierce the leaf tissue with a $1.55-\mathrm{mm}$ diameter steel rod. For each species we calculated the average of 5-10 measurements made on different leaves.

\section{Data analysis}

We quantified shredder abundance as density (i.e., number of shredder individuals divided by leaf litter dry mass in each sample) and relative abundance (i.e., number of shredder individuals divided by the number of all individuals, including both shredders and nonshredders, in each sample). Non-shredder data were unavailable for Hong Kong. Shredder taxon richness was quantified as the number of shredder morphospecies per sample. We adjusted richness values for Hong Kong samples, which were larger than those of other regions $\left(0.09 \mathrm{~m}^{2}\right.$ vs. $\left.0.04 \mathrm{~m}^{2}\right)$, by means of rarefaction in $\mathrm{PC}$ ORD (McCune and Mefford 2006). We further recorded the density and richness of shredders of each order (Amphipoda, Blattodea, Coleoptera, Decapoda, Diptera, Ephemeroptera, Lepidoptera, Plecoptera, Prosobranchia, and Trichoptera).

We tested our first hypothesis (that shredders are more abundant and diverse in temperate than in tropical streams) by examining variation in shredder density ( $\log _{e}$-transformed), relative abundance (arcsine squareroot transformed), and taxon richness with mixed model ANOVAs followed by post hoc Tukey tests. Region (nested within climate zone) and site (nested within region) were included in the models as random factors, while climate zone and habitat type (riffle or pool) were fixed factors. Habitat type was included in the models to 
investigate whether the expected pattern of shredders being more abundant in (but not restricted to) pools (e.g., as in tropical Queensland; Cheshire et al. 2005) was supported. We also included the interaction climate zone $\times$ habitat type to see if this pattern holds across climate zones.

To further examine the first hypothesis, we explored the variation in the density ( $\log _{e}$-transformed) and richness of different orders between climate zones with two-way ANOVAs; climate zone and order were the factors and we were interested in the interaction, to investigate whether latitudinal patterns differ for different orders. A similar model was used to explore the interaction order $\times$ biogeographic realm (realms listed in Table 1). We also explored the distribution of shredder assemblage composition with non-metric multidimensional scaling (NMDS), using fourth-root-transformed family abundance data in each region and the Sørensen (Bray-Curtis) distance measure in the PC-ORD package (McCune and Mefford 2006). The contribution of each family to NMDS axes was explored with nonparametric Spearman correlations. We tested the null hypothesis of no difference in position in multidimensional space between climate zones and among biogeographic realms, using multi-response permutation procedures (MRPP), also in PC-ORD.

To examine the second hypothesis (that shredder distribution in tropical streams is limited by temperature and availability of palatable litter) we explored the relationship of temperature (water temperature, air temperature of the coldest and hottest month, and seasonal temperature variability) and leaf litter characteristics (mean, minimum, and maximum leaf toughness, and morphospecies richness of leaf litter and of riparian trees) with shredder assemblages (density, relative abundance, taxon richness, and assemblage composition [summarized as the scores of NMDS axes]), using nonparametric Spearman correlations. We also examined the variation in temperature and litter characteristics (all the variables listed above) between climate zones with one-way ANOVAs.

\section{RESULTS}

We collected a total of 76892 invertebrates in 1295 leaf litter samples. Twenty-four percent were classified as shredders. The proportion of vascular plant tissue in shredder gut contents was $72 \% \pm 4 \%$ (mean $\pm \mathrm{SE}$ ). Mean shredder densities were $3.4 \pm 0.3$ and $1.3 \pm 0.3$ individuals $/ \mathrm{g}$ of leaf litter at temperate and tropical sites, respectively. Densities were higher in the temperate zone, even though variation at the region and site scales was similarly high (Table 2). The highest densities within the temperate zone occurred in France (Fig. 1A), and within the tropical zone in Hong Kong and Ecuador (Fig. 1B). Shredder densities were higher in pools than in riffles, but a significant interaction indicated that this difference between habitats was only significant in the temperate zone (Table 2).
Shredders were $39 \%$ of all leaf litter invertebrates in the temperate zone and $15 \%$ in the tropical zone. Their relative abundance in leaf litter samples was higher in the temperate zone, although variation was higher at the region and site scales than at the climate zone scale (Table 2). The highest relative abundances within the temperate zone occurred in Portugal and France (Fig. 1C), and within the tropical zone in Queensland, northeastern Australia (Fig. 1D). Shredder relative abundances were higher in pools than in riffles, with no differences between climate zones (Table 2).

We identified a total of 133 shredder morphospecies belonging to 40 families, of which 19 were present at temperate sites and 31 were present at tropical sites (Appendix A). The mean number of shredder morphospecies per sample was $2.9 \pm 0.1$ and $1.25 \pm 0.04$ at temperate and tropical sites, respectively; it was significantly higher in the temperate zone, although variation was higher among regions within climate zones (Table 2). The highest richness within the temperate zone occurred in France (Fig. 1E), and within the tropical zone in India, Queensland, Colombia, and Ecuador (Fig. 1F). Shredder richness did not differ between riffle and pool habitats (Table 2).

The Trichoptera was the order with the highest number of families (11) including shredder species, followed by Plecoptera (8), Coleoptera (7), Decapoda (5), Diptera (2), Prosobranchia (2), Amphipoda (2), Ephemeroptera (1), Lepidoptera (1), and Blattodea (1). All orders except Amphipoda were present in the tropical zone, while Prosobranchia and Blattodea were absent from the temperate zone (Appendix A). Densities of shredders belonging to different orders differed between climate zones, as indicated by the significant interaction between climate zone and order $\left(F_{9,1419}=\right.$ 45.4, $P<0.0001)$. In temperate regions, the most abundant order was the Plecoptera, followed by Amphipoda and Trichoptera; in tropical regions, the most abundant order was the Trichoptera, followed by Coleoptera and Prosobranchia. Richness of shredders belonging to different orders also differed between climate zones $\left(F_{9,1469}=32.7, P<0.0001\right)$. In the temperate zone, the Plecoptera and Trichoptera were the richest shredder orders; in the tropical zone, the order with highest richness was the Trichoptera, followed by Coleoptera, Diptera, and Decapoda. Density and richness of shredders of different orders also varied among biogeographic realms (density, $F_{36,1419}=15.5, P$ $<0.0001$; richness, $\left.F_{36,1469}=14.1, P<0.0001\right)$. The Trichoptera were most abundant and rich in morphospecies in the Australian realm; the Plecoptera and Amphipoda in the Paleartic; the Coleoptera in the Neotropical; and the Prosobranchia and Decapoda in the Indomalayan realm.

The NMDS ordination produced a three-dimensional solution (stress $=0.081)($ Fig. 2). Axis 1 explained the largest proportion of the variation $(43 \%)$; it was inversely related to the abundance of Limnephilidae 
TABLE 2. Results of mixed-model ANOVAs exploring variation in shredder densities ( $\log _{e}$-transformed), relative abundance (arcsine square-root transformed), and taxon richness between climate zones (temperate and tropical), among study regions (nested within climate zone), among sites (nested within region), with habitat type (riffles and pools), and the interaction between climate zone and habitat type.

\begin{tabular}{|c|c|c|c|c|c|}
\hline Source of variation & df & SS & $F$ & $P$ & Variance explained (\%) \\
\hline \multicolumn{6}{|l|}{ Shredder density } \\
\hline Climate zone & 1 & 123.0 & 9.46 & $<0.001$ & 18 \\
\hline Region (climate zone) & 12 & 156.0 & 12.85 & $<0.0001$ & 23 \\
\hline Site (region (climate zone)) & 115 & 116.3 & 4.19 & $<0.0001$ & 17 \\
\hline Habitat & 1 & 3.1 & 12.65 & $<0.001$ & \\
\hline Climate zone $\times$ habitat & 1 & 1.2 & 5.15 & 0.02 & \\
\hline Error & 1164 & 280.9 & & & 42 \\
\hline \multicolumn{6}{|l|}{ Shredder relative abundance } \\
\hline Climate zone & 1 & 26.5 & 7.29 & 0.02 & 17 \\
\hline Region (climate zone) & 12 & 43.7 & 13.29 & $<0.0001$ & 27 \\
\hline Site (region (climate zone)) & 112 & 30.7 & 5.18 & $<0.0001$ & 19 \\
\hline Habitat & 1 & 1.0 & 18.89 & $<0.0001$ & \\
\hline Climate zone $\times$ habitat & 1 & $<0.1$ & 0.49 & 0.48 & \\
\hline Error & 1094 & 57.9 & & & 37 \\
\hline \multicolumn{6}{|l|}{ Shredder taxon richness } \\
\hline Climate zone & 1 & 545.7 & 6.21 & 0.03 & 16 \\
\hline Region (climate zone) & 12 & 1054.3 & 23.06 & $<0.0001$ & 32 \\
\hline Site (region (climate zone)) & 115 & 438.2 & 3.38 & $<0.0001$ & 13 \\
\hline Habitat & 1 & 4.9 & 4.32 & 0.04 & \\
\hline Climate zone $\times$ habitat & 1 & 2.7 & 2.42 & 0.12 & \\
\hline Error & 1164 & 1309.4 & & & 39 \\
\hline
\end{tabular}

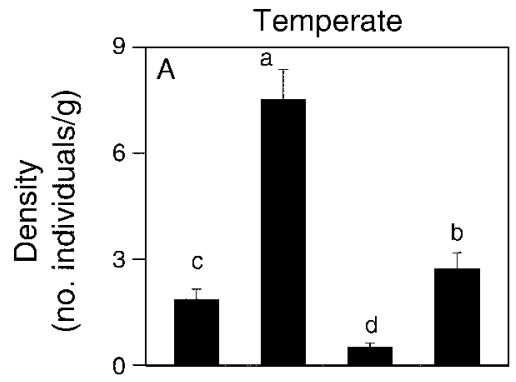

Tropical
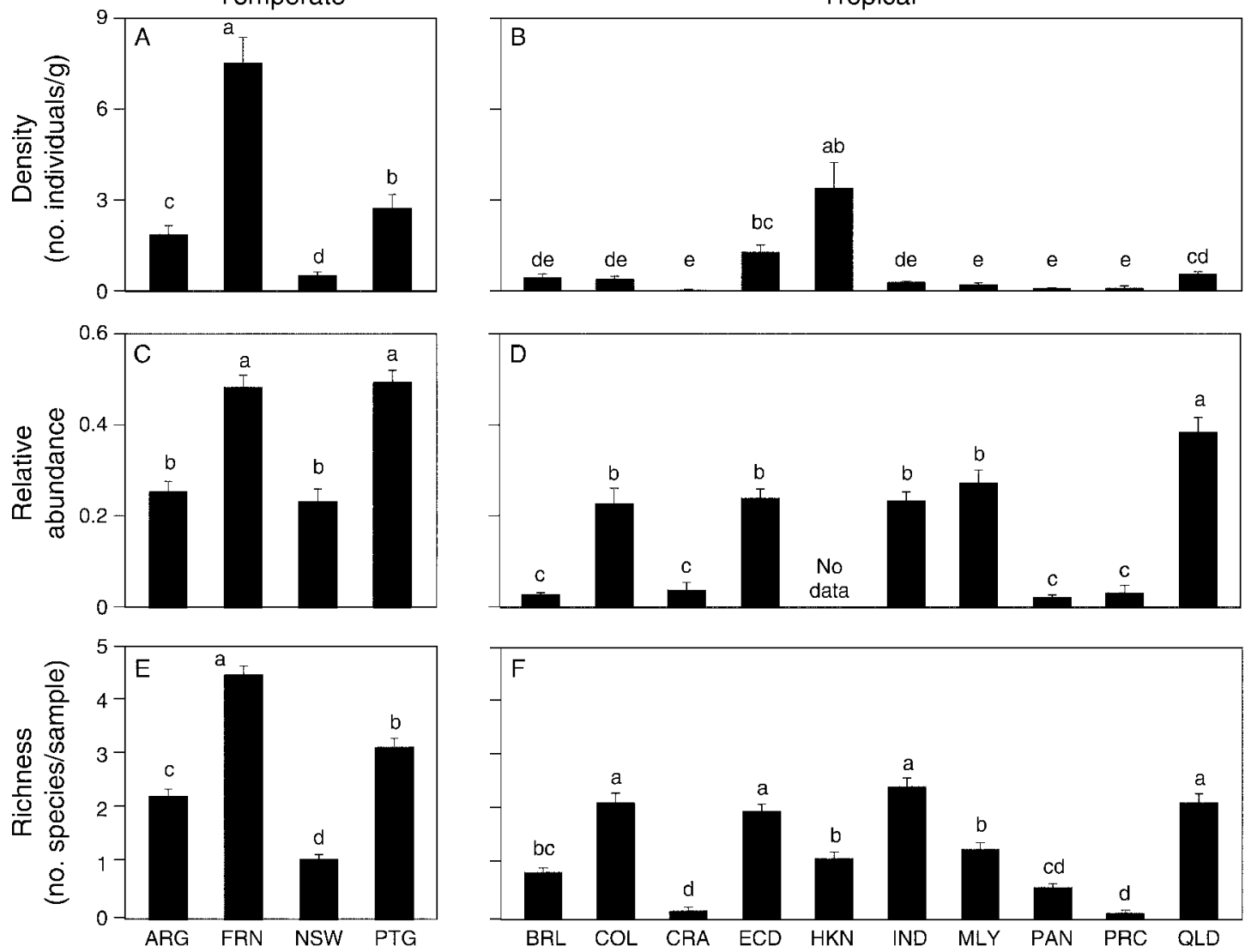

FIG. 1. (A, B) shredder density, (C, D) relative abundance, and (E, F) taxon richness in (A, C, E) temperate and (B, D, F) tropical study regions (see Table 1 for acronyms). Values shown are means + SE. Different lowercase letters denote significant differences as indicated by post hoc Tukey tests. 


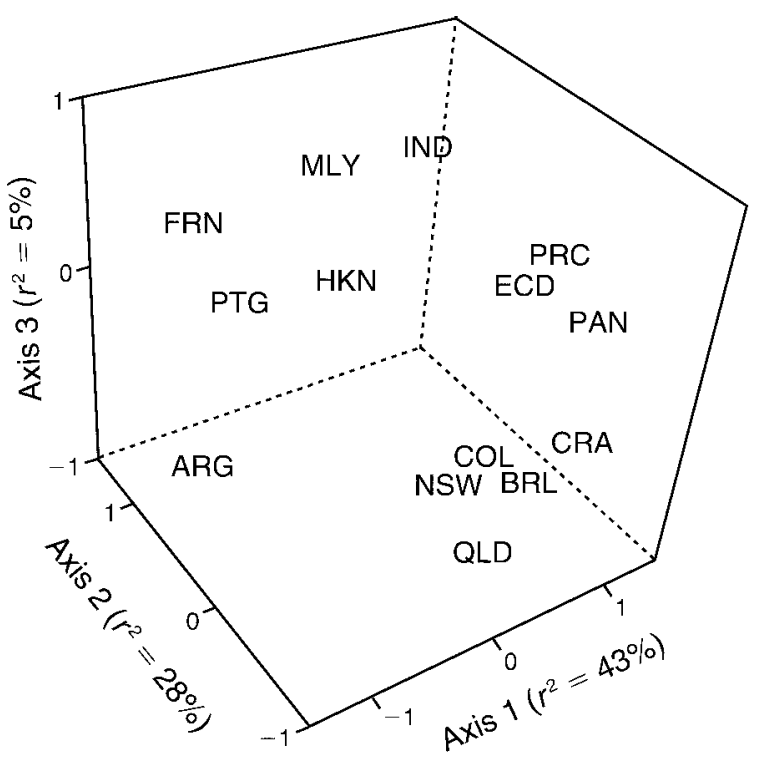

FIG. 2. Nonmetric multidimensional scaling (NMDS) ordination of study regions (see Table 1 for acronyms) in taxonomic space (fourth-root-transformed abundance data), based on a three-dimensional solution (stress $=0.081$ ). Variation explained by each axis $\left(r^{2}\right.$, expressed as a percentage) is also shown.

(Spearman's $\rho=-0.79, P=0.0007)$, Tipulidae $(\rho=$ $-0.57, P=0.032)$, Nemouridae $(\rho=-0.57, P=0.034)$, and Sericostomatidae $(\rho=-0.56, P=0.036)$. Axis 2 explained $28 \%$ of the variation and was directly related to the abundance of Nemouridae $(\rho=0.80, P=0.0006)$, Lepidostomatidae $(\rho=0.78, P=0.001)$, Leuctridae $(\rho=$ $0.72, P=0.004)$, and Limnephilidae $(\rho=0.63, P=$ $0.016)$, and inversely related to Ptilodactylidae $(\rho=$ $-0.78, P=0.001)$ and Odontoceridae $(\rho=-0.60, P=$ 0.023 ). Axis 3 explained $5 \%$ of the variation and was directly related to Paratelphusidae $(\rho=0.60, P=0.023)$, Thiaridae $(\rho=0.60, P=0.023)$, and Lepidostomatidae ( $\rho=0.57, P=0.035)$, and inversely related to Leptoceridae $(\rho=-0.84, P=0.0002)$. Samples from the different biogeographic realms grouped together, with minor overlap between the Australian and Neotropical regions, and between the Palearctic and Indomalayan regions. MRPP confirmed the contrasts between biogeographic realms $(A=0.110, P<0.0001)$, with all pairwise comparisons being highly significantly different $(P<0.01$; Table 3$)$. The difference between temperate and tropical groups was also highly significant (MRPP, $A=0.103, P<0.0001$ ).

Shredder assemblages were strongly related to temperature: density was related to water temperature ( $\rho=$ $-0.76, P<0.0001)$, seasonal temperature variability $(r=$ $0.76, P=0.003)$, and the mean temperature of the coldest month $(\rho=-0.74, P=0.004)$; relative shredder abundance, richness, and NMDS axis 1 to water temperature $(\rho=-0.49, P<0.0001 ; \rho=-0.63, P<$ 0.0001 ; and $\rho=0.60, P=0.022$, respectively); and
NMDS axis 2 , to seasonal temperature variability $(\rho=$ $0.58, P=0.039$ ). Water temperature was $8.3^{\circ} \mathrm{C} \pm 0.6^{\circ} \mathrm{C}$ and $20.1^{\circ} \mathrm{C} \pm 0.4^{\circ} \mathrm{C}$ at temperate and tropical sites, respectively (Fig. 3A); it was significantly higher in the tropical zone $\left(F_{1,130}=227.3, P<0.0001\right)$. Mean water temperature of the coldest and hottest month were, respectively, $11.0^{\circ} \mathrm{C} \pm 4.2^{\circ} \mathrm{C}$ and $20.3^{\circ} \mathrm{C} \pm 1.3^{\circ} \mathrm{C}$ in the temperate zone, and $21.3^{\circ} \mathrm{C} \pm 2.5^{\circ} \mathrm{C}$ and $25.0^{\circ} \mathrm{C} \pm 0.9^{\circ} \mathrm{C}$ in the tropical zone (Fig. 3A); the mean temperature of the coldest month was significantly higher in the tropical zone $\left(F_{1,11}=8.0, P=0.016\right)$, whereas the mean temperature of the hottest month was not significantly different $\left(F_{1,11}=3.0, P=0.11\right)$. Seasonal temperature variability was $0.3 \pm 0.1$ in the temperate zone and 0.07 \pm 0.02 in the tropical zone (Fig. $3 \mathrm{~B}$ ); it was significantly higher in the temperate zone $\left(F_{1,11}=9.7, P=0.0097\right)$.

Shredder assemblages were not related to leaf toughness, but they were related to richness of morphospecies in the stream litter and riparian vegetation. Shredder density was related to litter $(\rho=-0.46, P$ $<0.0001)$ and riparian richness $(\rho=-0.45, P<0.0001)$; and so were shredder relative abundance (litter $\rho=$ $-0.40, P<0.0001$; riparian $\rho=-0.51, P<0.0001)$ and richness (litter $\rho=-0.57, P<0.0001$; riparian $\rho=-0.51$, $P<0.0001)$.

Mean, minimum, and maximum leaf toughness were, respectively, $1303 \pm 223 \mathrm{kPa}, 825 \pm 127 \mathrm{kPa}$, and 2145 $\pm 542 \mathrm{kPa}$ (Fig. 3C). None of these variables varied significantly between climate zones (mean toughness, $F_{1,11}=0.80, P=0.39$; minimum toughness, $F_{1,11}=0.31$, $P=0.59$; maximum toughness, $\left.F_{1,11}=1.33, P=0.28\right)$. Mean leaf litter richness was $7.0 \pm 0.6$ and $13.0 \pm 1.2$ species per sample at temperate and tropical sites, respectively (Fig. 3D); it was significantly higher in the tropical zone $\left(F_{1,95}=16.8, P<0.0001\right)$. Richness of riparian trees was $12.4 \pm 0.9$ and $25.8 \pm 1.6$ morphospecies per site at temperate and tropical sites, respectively (Fig. 3D); it was significantly higher in the tropical zone $\left(F_{1,103}=32.0, P<0.0001\right)$.

\section{DisCusSION}

Our results demonstrate that the shredder trophic guild, which plays a key role in the functioning of stream

TABLE 3. Differences among biogeographic realms in shredder density and taxon richness of different animal orders as revealed by multi-response permutation procedures (MRPP).

\begin{tabular}{lll}
\hline \hline \multicolumn{1}{c}{ Order } & Shredder density & Shredder taxon richness \\
\hline Trichoptera & Au > Af, I & Au > Af, I \\
& N, P > Af & I, N, P > Af \\
Plecoptera & P > Af, Au, I, N & P > Af, Au, I, N \\
Coleoptera & N > Au, I & N > Af, Au \\
Decapoda & - & I > Af, N, P \\
Prosobranchia & I > Af, Au, N, P & I > N \\
Amphipoda & P > Af, Au, I, N & - \\
\hline
\end{tabular}

Notes: Dash (-) indicates no difference. No differences were found for Blattodea, Diptera, Ephemeroptera, and Lepidoptera. Biogeographic realms are: Af, Afrotropical; Au, Australian; I, Indomalayan; N, Neotropical; P, Palearctic. 

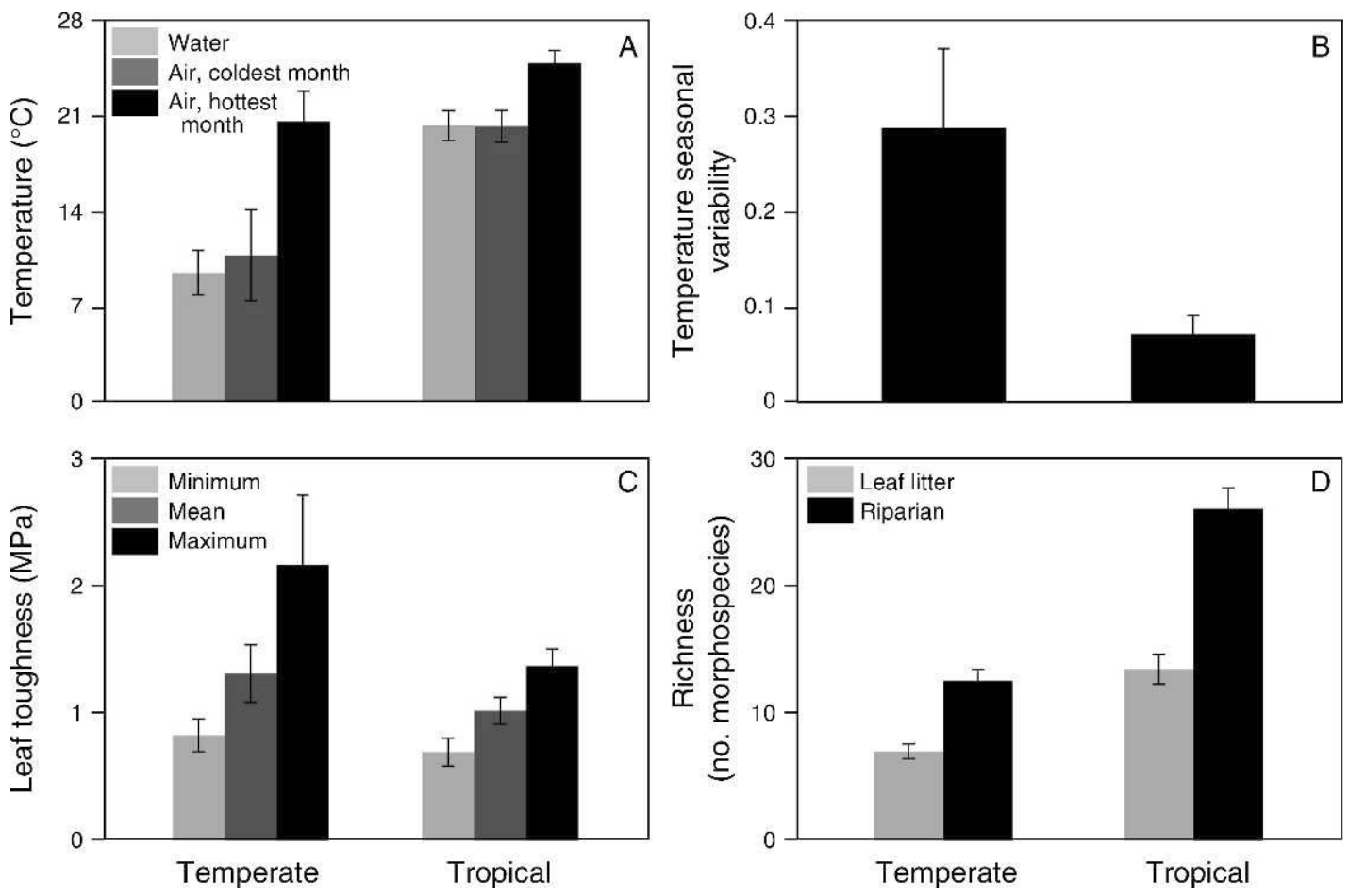

FIG. 3. (A) Water temperature (mean in each region, recorded in the field) and air temperature (mean of the coldest and hottest month, from the nearest weather station); (B) seasonal variability of air temperature (from the nearest weather station, expressed as the coefficient of variation); (C) leaf toughness (minimum, mean, and maximum of the three most common tree species in each region); and (D) morphospecies richness of leaf litter samples in streams and of riparian trees. Error bars show \pm SE.

ecosystems, is generally more prevalent and diverse in temperate climates. This pattern contrasts sharply with the common latitudinal gradient of higher richness toward the equator, shared by most taxonomic groups such as mammals, birds, reptiles, amphibians, fishes, tunicates, crustaceans, insects, mollusks, brachiopods, corals, foraminiferans, and vascular plants (Lyons and Willig 2002). The few exceptions to this trend usually emerge at lower levels in the systematic hierarchy (e.g., seals, penguins, voles, salamanders, ichneumonid wasps, conifers [Lyons and Willig 2002]; and within freshwater habitats, stoneflies and, to a lesser extent, mayflies [Pearson and Boyero 2009]), suggesting that global diversity patterns depend on the classification of species used. Our results indicate that exploring distribution patterns within trophic guilds, i.e., groups of taxa that use a particular subset of food resources, may provide a useful new perspective to the study of latitudinal diversity gradients. This approach is more explicit about species packing, and it facilitates exploration of mechanisms by minimizing potentially confounding variables related to the resources used.

Our results also show that, despite a general trend of higher shredder prevalence in temperate areas, variation at the regional scale is important, particularly within the tropics. This can explain the contrasting results of different tropical local studies (Jacobsen et al. 2008, Boyero et al. 2009). We found very low shredder richness is some tropical regions, all in Central America and the Caribbean, but not in others in South America, Asia, and Australia. Shredder richness was particularly high in our European regions (France and Portugal), which supports previous findings for other regions not included in this study (e.g., Sweden [Jonsson et al. 2001], Britain [Dobson et al. 2002]). We were unable to include sites from North America in this study, but we would expect shredder richness in this region to be at least as high as in Europe, based on existing evidence (Wiggins and Mackay 1978, Merritt et al. 2008). This suggests that shredder distribution is related to biogeography as well as to latitude, which is in agreement with patterns of shredder assemblage composition observed here. For example, the Trichoptera were most abundant and diverse in the Australian realm, supporting previous observations (Vinson and Hawkins 2003). The Plecoptera were prevalent in the Palearctic realm, also supporting existing evidence (e.g., Gessner and Dobson 1993, Jonsson et al. 2001). It is also possible that variation in shredder biomass and turnover might explain differences in shredder abundance and diversity between and within climate zones, but currently we do not have sufficient data to test this hypothesis. The fact that higher shredder densities in pools only occurred in temperate streams also merits further attention, particularly as shredder richness was similar in riffles and pools across climate zones. This suggests that particular 


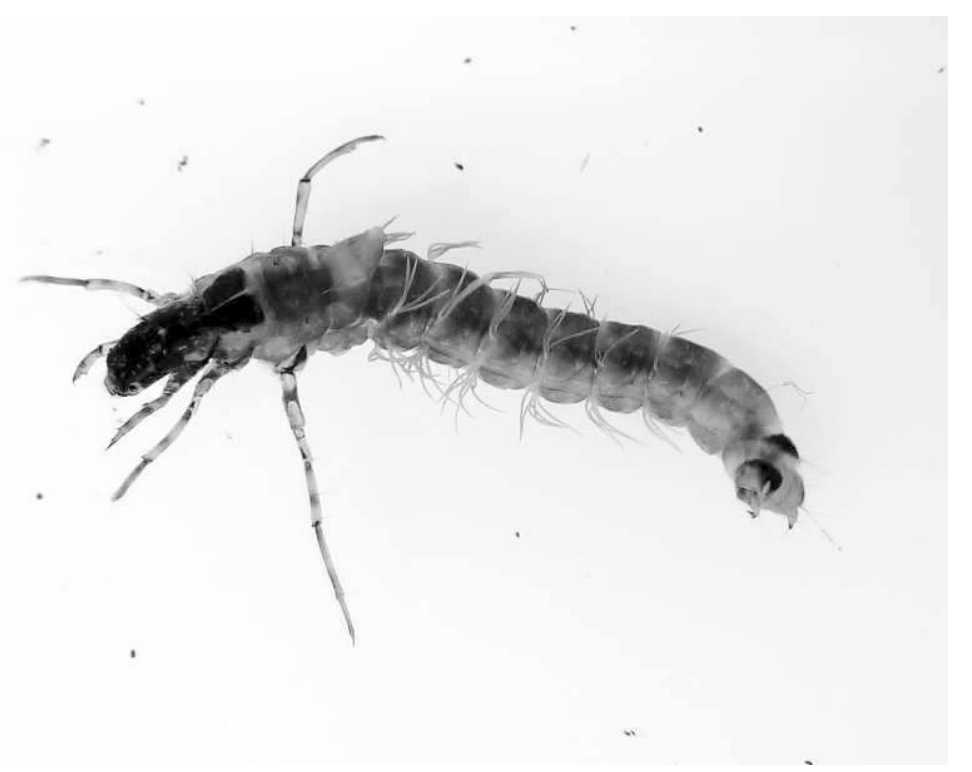

Plate 1. Stream shredder of the species Calamoceras marsupus (Calamoceratidae) from southern Spain. Photo credit: L. Boyero.

species occur in high densities in pools of temperate streams, which is possibly related to the existence of large patches of palatable leaves (Graça 2001).

This study also supports the notion that an inverse relationship exists between shredder richness and water temperature, implying that adaptation to cool waters might limit shredder distribution in the tropics for physiological reasons (Dobson et al. 2002). A tendency toward higher shredder densities in regions where the mean temperature of the coldest month was lower lends further support to this hypothesis. In addition, the taxonomic composition of shredder assemblages was related to water temperature (NMDS axis 1) and to seasonal temperature variability (NMDS axis 2), further underlining the importance of temperature regimes for the distribution of several taxa (Limnephilidae, Tipulidae, Nemouridae, and Sericostomatidae, which were aligned along NMDS axis 1 in a way reflecting their main distribution in cool waters). These are all taxa typical of temperate regions, and in the tropics they have only been recorded at high elevations (Yule et al. 2009). Other taxa were aligned along NMDS axis 2, reflecting their main distribution in areas with either high or low seasonal temperature variability, i.e., their distribution in either the temperate (Nemouridae, Lepidostomatidae, Leuctridae, and Limnephilidae) or tropical zone (Ptilodactylidae and Odontoceridae). Nevertheless, it is unlikely that temperature per se fully explains global patterns of shredder distribution, because reduced species numbers in warmer waters would reduce interspecific competition. As a result, populations of the species present could exploit a larger resource pool (given similar levels of resource supply), suggesting that total shredder densities need not necessarily be lower than in cooler sites. This suggests that factors other than water temperature influence variation in shredder abundance among sites as well.

That leaf toughness was similar in tropical and temperate sites is in accordance with results from a comparison of 2819 plant species across 90 sites worldwide (Onoda et al. 2011), and we found no relationship between leaf toughness and shredder abundance or richness. This does not necessarily mean that shredder distribution is unaffected by leaf quality, but it might point to a greater importance of chemical than mechanical leaf defenses (Onoda et al. 2011). There is evidence from terrestrial systems that secondary metabolites such as tannins may be a crucial determinant of leaf litter utilization (Coq et al. 2010) and some similar evidence is also available for leaf litter in streams (Ostrofsky 1997, Schweitzer et al. 2008). Nutrient concentration in leaves ( $\mathrm{N}$ and $\mathrm{P}$ ) can also play a role in shredder distribution across latitudes; if it declined with decreasing latitude, mirroring the overall nutrient poverty of tropical soils (Reich and Oleksyn 2004), then tropical shredders would encounter poorer-quality food than their temperate counterparts and experience greater stoichiometric imbalances that could limit their abundance and diversity. This nutrient limitation effect could be reinforced by a greater fraction of evergreen species at tropical latitudes, whose leaves tend to have lower leaf $\mathrm{N}$ and $\mathrm{P}$ content than deciduous leaves (Reich and Oleksyn 2004). Effects of leaf quality on shredder distribution are thus likely to be complex and remain inconclusive at present.

We found evidence of an inverse relationship of shredder abundance and diversity with riparian tree richness, as well as with litter richness in the stream. 
Both were higher in our tropical sites, as expected. Higher litter diversity, in combination with a lower average quality of leaves, would make palatable litter scarcer in tropical streams. This relationship is striking because it contradicts the general rule of higher consumer diversity at higher levels of resource diversity (Loreau and Hector 2001). However, it concurs with other stream studies that have found that litter diversity alone does not explain invertebrate diversity patterns (LeRoy and Marks 2006, Kominoski and Pringle 2009). This issue merits further examination, particularly to assess the possible consequences of riparian species loss for shredder assemblages and leaf litter dynamics in streams (Gessner et al. 2010).

Understanding how trophic guilds are distributed across the globe as a result of climate, biogeography, and many other factors, is essential for predicting the effects of environmental change on ecosystem functioning. Headwater forest streams typically represent a large proportion of river networks (Clarke et al. 2008), and provide fine particulate organic matter to downstream reaches via decomposition pathways (Heard and Richardson 1995). It is crucial, therefore, to understand and quantify such ecological relationships in headwaters for underpinning stream conservation and management measures. However, the complexity of interactions between environmental constraints, the quality and availability of resources, and biogeography is such that establishing clear causal relationships with global shredder distribution patterns remains an important challenge. For example, it is important to further clarify the effect of water temperature on shredder numbers and diversity if effects of global warming on stream ecosystem functioning are to be accurately forecast. Shredder-mediated litter decomposition rates are reduced at low latitudes (Boyero et al. 2011), and this could be partly explained by the lower abundance and diversity of tropical shredders observed here.

\section{ACKNOWLedgments}

Z. Dewson, G. Cabarcas, W. Cardona, M. Dunfee, B. Gao, L. Giraldo, Y. González, M. Hirose, A. O. Y. Li, P. Lisle, N. Mochizuki, D. Nawa, L. C. Y. Ng, P. Rosa, R. SánchezArgüello, and K. Schmidt assisted with field work. N. Connolly designed the penetrometer, which was constructed by R. Gegg at James Cook University (Australia). The study was supported by a grant from the National Geographic Society's Committee for Research and Exploration (grant number 7980-06; P.I., L. Boyero; funds went to sites in Latin America [except Puerto Rico], Africa, and Asia [except Hong Kong]) and various national funding sources.

\section{Literature Cited}

Arita, H. T., and E. Vázquez-Domínguez. 2008. The tropics: cradle, museum or casino? A dynamic null model for latitudinal gradients of species diversity. Ecology Letters 11:653-663.

Boyero, L., et al. 2011. A global experiment suggests climate warming will not accelerate litter decomposition in streams but might reduce carbon sequestration. Ecology Letters 14:289-294.
Boyero, L., A. Ramírez, D. Dudgeon, and R. G. Pearson. 2009. Are tropical streams really different? Journal of the North American Benthological Society 28:397-403.

Camacho, R., L. Boyero, A. Cornejo, A. Ibáñez, and R. G. Pearson. 2009. Local variation in shredder distribution can explain their oversight in tropical streams. Biotropica 41:625-632.

Cheshire, K., L. Boyero, and R. G. Pearson. 2005. Food webs in tropical Australian streams: shredders are not scarce. Freshwater Biology 50:748-769.

Chung, N., and K. Suberkropp. 2009. Contribution of fungal biomass to the growth of the shredder, Pycnopsyche gentilis (Trichoptera: Limnephilidae). Freshwater Biology 54:22122229.

Clarke, A., R. Mac Nally, N. Bond, and P. S. Lake. 2008. Macroinvertebrate diversity in headwater streams: a review. Freshwater Biology 53:1707-1721.

Coley, P. D., and J. A. Barone. 1996. Herbivory and plant defenses in tropical forests. Annual Review of Ecology and Systematics 27:305-335.

Coq, S., J. M. Souquet, E. Meudec, V. Cheynier, and S. Hättenschwiler. 2010. Interspecific variation in leaf litter tannins drives decomposition in a tropical rain forest of French Guiana. Ecology 91:2080-2091.

Cornwell, W. K., et al. 2008. Plant species traits are the predominant control on litter decomposition rates within biomes worldwide. Ecology Letters 11:1065-1071.

Cummins, K. W. 1974. Structure and function of stream ecosystems. BioScience 24:631-641.

Cummins, K. W., and M. J. Klug. 1979. Feeding ecology of stream invertebrates. Annual Review of Ecology and Systematics 10:147-172.

Cummins, K. W., M. A. Wilzbach, D. M. Gates, J. B. Perry, and W. B. Taliaferro. 1989. Shredders and riparian vegetation: leaf litter that falls into streams influences communities of stream invertebrates. BioScience 39:24-30.

Dobson, M., J. M. Mathooko, A. Magana, and F. K. Ndegwa. 2002. Macroinvertebrate assemblages and detritus processing in Kenyan highland streams: more evidence for the paucity of shredders in the tropics? Freshwater Biology 47:909-919.

Dudgeon, D. 1994. The influence of riparian vegetation on macroinvertebrate community structure and functional organization in six New Guinea streams. Hydrobiologia 294:65-85.

Fuhrman, J. A., J. A. Steele, I. Hewson, M. S. Schwalbach, M. V. Brown, and J. L. Green, and J. H. Brown. 2008. A latitudinal diversity gradient in planktonic marine bacteria. Proceedings of the National Academy of Sciences USA 105:7774-7778.

Gessner, M. O., and M. Dobson. 1993. Colonisation of fresh and dried leaf litter by lotic macroinvertebrates. Archiv für Hydrobiologie 127:141-149.

Gessner, M. O., C. M. Swan, C. K. Dang, B. G. McKie, R. D. Bardgett, D. H. Wall, and S. Hättenschwiler. 2010. Diversity meets decomposition. Trends in Ecology and Evolution 25:372-380.

Gonçalves, J. F., Jr., M. A. S. Graça, and M. Callisto. 2006. Leaf-litter breakdown in 3 streams in temperate, Mediterranean, and tropical Cerrado climates. Journal of the North American Benthological Society 25:344-355.

Graça, M. A. S. 2001. The role of invertebrates on leaf litter decomposition in streams: a review. International Review of Hydrobiology 86:383-393.

Grime, J. P., J. H. C. Cornelissen, K. Thompson, and J. G. Hodgson. 1996. Evidence of a causal connection between anti-herbivore defence and the decomposition rate of leaves. Oikos 77:489-494.

Heard, S. B., and J. S. Richardson. 1995. Shredder-collector facilitation in stream detrital food webs: is there enough evidence. Oikos 72:359-366. 
Hieber, M., and M. O. Gessner. 2002. Contribution of stream detrivores, fungi, and bacteria to leaf breakdown based on biomass estimates. Ecology 83:1026-1038.

Hillebrand, H. 2004. On the generality of the latitudinal diversity gradient. American Naturalist 163:192-211.

Jacobsen, D., C. Cressa, J. M. Mathooko, and D. Dudgeon. 2008. Macroinvertebrates: composition, life histories and production. Pages 66-105 in D. Dudgeon, editor. Tropical stream ecology. Academic Press, San Diego, California, USA.

Jonsson, M., B. Malmqvist, and P. O. Hoffsten. 2001. Leaf litter breakdown rates in boreal streams: Does shredder species richness matter? Freshwater Biology 46:161-171.

Kominoski, J. S., and C. M. Pringle. 2009. Resource-consumer diversity: testing the effects of leaf litter species diversity on stream macroinvertebrate communities. Freshwater Biology 54:1461-1473.

Landeiro, V. L., N. Hamada, and A. S. Melo. 2008. Responses of aquatic invertebrate assemblages and leaf breakdown to macroconsumer exclusion in Amazonian "terra firme" streams. Fundamental and Applied Limnology 172:49-58.

LeRoy, C. J., and J. C. Marks. 2006. Litter quality, stream characteristics and litter diversity influence decomposition rates and macroinvertebrates. Freshwater Biology 51:605617.

Li, A. O. Y., and D. Dudgeon. 2008. Food resources of shredders and other benthic macroinvertebrates in relation to shading conditions in tropical Hong Kong streams. Freshwater Biology 53:2011-2025.

Loreau, M., and A. Hector. 2001. Partitioning selection and complementarity in biodiversity experiments. Nature $412: 72-$ 76.

Lyons, S. K., and M. R. Willig. 2002. Species richness, latitude, and scale sensitivity. Ecology 83:47-58.

Mathuriau, C., and E. Chauvet. 2002. Breakdown of leaf litter in a Neotropical stream. Journal of the North American Benthological Society 21:384-396.

McCune, B., and M. J. Mefford. 2006. PC-ORD. Multivariate analysis of ecological data. Version 5.10. MjM Software, Glenedon Beach, Oregon, USA.

Merritt, R. W., K. W. Cummins, and M. B. Berg. 2008. An introduction to the aquatic insects of North America. Fourth edition. Kendall Hunt, Dubuque, Iowa, USA.

Onoda, Y., et al. 2011. Global patterns of leaf mechanical properties. Ecology Letters 14:301-311.

Ostrofsky, M. L. 1997. Relationship between chemical characteristics of autumn-shed leaves and aquatic processing rates. Journal of the North American Benthological Society 16:750-759.
Passy, S. I. 2010. A distinct latitudinal gradient of diatom diversity is linked to resource supply. Ecology 91:36-41.

Pearson, R. G., and L. Boyero. 2009. Gradients in regional diversity of freshwater taxa. Journal of the North American Benthological Society 28:504-514.

Quian, H., and R. E. Ricklefs. 2007. A latitudinal gradient in large-scale beta diversity for vascular plants in North America. Ecology Letters 10:737-744.

Reich, P. B., and J. Oleksyn. 2004. Global patterns of plant leaf $\mathrm{N}$ and $\mathrm{P}$ in relation to temperature and latitude. Proceedings of the National Academy of Sciences USA 101:11001-11006.

Schweitzer, J. A., M. D. Madritch, J. K. Bailey, C. J. LeRoy, D. G. Fischer, B. J. Rehill, R. L. Lindroth, A. E. Hagerman, S. C. Wooley, S. C. Hart, and T. G. Whitham. 2008. From genes to ecosystems: the genetic basis of condensed tannins and their role in nutrient regulation in a Populus model system. Ecosystems 11:1005-1020.

Stevens, R. D. 2004. Untangling latitudinal richness gradients at higher taxonomic levels: familial perspectives on the diversity of New World bat communities. Journal of Biogeography 31:665-674.

Udvardy, M. D. F. 1975. A classification of the biogeographical provinces of the world. Occasional paper no. 18. IUCN, Morges, Switzerland.

Vinson, M. R., and C. P. Hawkins. 2003. Broad-scale geographical patterns in local stream insect genera richness. Ecography 26:751-767.

Wallace, J. B., S. L. Eggert, J. L. Meyer, and J. R. Webster. 1997. Multiple trophic levels of a forest stream linked to terrestrial litter inputs. Science 277:102-104.

Wantzen, K. M., R. Wagner, R. Suetfeld, and W. J. Junk. 2002. How do plant-herbivore interactions of trees influence coarse detritus processing by shredders in aquatic ecosystems of different latitudes? Verhandlungen der Internationalen Vereinigung fur Theoretische und Angewandte Limnologie 28:815-821.

Wiggins, G. B., and R. J. Mackay. 1978. Relationships between systematics and trophic ecology in Nearctic aquatic insects, with special reference to Trichoptera. Ecology 59:1211-1220.

Willig, M. R., D. M. Kaufman, and R. D. Stevens. 2003. Latitudinal gradients of biodiversity: pattern, process, scale, and synthesis. Annual Review of Ecology, Evolution and Systematics 34:273-309.

Yule, C. M., M. Y. Leong, L. Ratnarajah, K. Schmidt, H. M. Wong, R. G. Pearson, and L. Boyero. 2009. Shredders in Malaysia: abundance and richness are greater in cool highland tropical streams. Journal of the North American Benthological Society 28:404-415.

\section{APPENDIX A}

Species, families, and orders of invertebrate shredders collected, and regions at which they were present (Ecological Archives E092-154-A1).

\section{APPENDIX B}

Leaf toughness of studied plant species in temperate and tropical regions (Ecological Archives E092-154-A2). 